\title{
Applied Research on Undergraduates' Innovation and Entrepreneurial Ability
}

\author{
Xi Chen, Wei Qin
}

Xi'an University, Xi' an, Shaanxi, 710065

\begin{abstract}
Keywords: Undergraduate Innovation, Entrepreneurial Ability, Applied Research
\end{abstract}
\begin{abstract}
Under the background of innovation and entrepreneurship in our country at present, college students urgently need to cultivate and improve the ability of innovation and entrepreneurship. First of all, it explains how the undergraduates should have the ability of innovation and entrepreneurship, and points out the status quo of the students 'awareness of entrepreneurship and innovation. Second, through the analysis of the related factors of the ability of innovation and entrepreneurship, it highlights the ability of cultivating and improving the students' ability to innovate and start a business Necessity; Finally, deeply analyze and explain how to cultivate and improve college students' innovation and entrepreneurship ability.
\end{abstract}

\section{Introduction}

In the context of mergers and acquisitions of colleges and universities to expand the scale of enrollment, the original specialist students have been improved into the undergraduate institutions. In the process of application-oriented education to test the water, the size of these students can not be ignored. Relative specialist education, the quality of these students will be significantly improved, but compared to the original traditional undergraduate colleges and universities, these students will have shortcomings in the competitiveness of employment is not optimistic. Entering the 21st century, the annual number of graduates of ordinary colleges and universities in our country has exceeded 5 million. In 2016, the number of graduates in the country reached 7.65 million, and the employment environment is extremely harsh. On December 13, 2016, according to the Report of 2015-2016 on China's Graduate Employment and Entrepreneurship Development, the net employment rate of graduates is $90.58 \%$, the average monthly salary is 3,869 yuan, and the net signing rate is only $68.64 \%$, Undergraduate progression rate was $14.91 \%$. The other data show that job satisfaction of the graduates in 2016 was $73.88 \%$, professional matching was $67.97 \%$, the more experienced the student cadres, the better the academic performance of graduates job search shorter time. In the context of the gradual increase in the number of graduates year after year, the phenomenon of unemployed graduates are also increasing year by year. Facing the complex and ever-changing employment situation, contemporary undergraduates, especially applied undergraduates, must establish an awareness of innovation and entrepreneurship from the beginning of four years of undergraduate study to improve their overall quality comprehensively. Applied education should also emphasize cultivating and improving the ability of innovation and entrepreneurship in order to increase the competitiveness of students and create conditions for them to confidently go to society. On the other hand, despite the pressure of employment, many enterprises find it difficult to recruit people, especially for productive enterprises, which require skilled personnel.

\section{Analysis and status of innovation and entrepreneurship}

Innovation does not require us to make things that even scientists can hardly make. It only requires us to learn in a down-to-earth manner. Only in the process of learning, we can have independent thinking, be able to use what we learn flexibly, Adjusting and adapting to the effect of innovation to meet real needs is an ability to innovate that uses knowledge at a higher level. Entrepreneurship is the highest form of employment channels. He is the process by which entrepreneurs create value by identifying and identifying business opportunities, setting up activities 
and using resources. The quality requirements of entrepreneurship for entrepreneurs are many and demanding. Entrepreneurs need more responsibility and risk, and have higher social and innovative entrepreneurship ability. According to the survey, some college students in our country lack of awareness of innovation and entrepreneurship, mainly reflected in: lack of awareness of innovation and desire to innovate; lack of basic knowledge of innovation; lack of innovative interest; lack of innovative thinking skills: lack of Innovation necessary perseverance. These students have a more one-sided understanding of entrepreneurship. They either over-look at starting a business or underestimate the importance of starting a business. This overconfidence and low self-esteem mentality is very difficult to adapt to the social challenges that are about to enter. These students tend to blindly start a business, just to catch up with the trend even comparisons heart. They lack rational analysis and judgment on their own capabilities and the objective conditions needed for starting a business. In addition, with the development of the Internet, the temptation around the students increases, the contemporary college students' ideology has become more complex and changeable. The lack of moral cultivation and the appearance of various psychological problems all contribute to the cultivation and improvement of innovative ability in education Set a barrier. In this case, entrepreneurship is undoubtedly more than a failure, and ideologically and empirically, they often can not afford such a blow. In the face of such severe employment pressure and social environment, the requirements for innovation and entrepreneurship of contemporary college students are getting higher and higher. Through education reform to improve contemporary college students' innovation, entrepreneurial ability without delay.

\section{Necessity of College Students' Innovation and Entrepreneurship}

The improvement of entrepreneurial capacity can expand the scope of employment of students to ease the pressure of employment. Entrepreneurial competence is the entrepreneur's ability to survive and develop in entrepreneurial practice. Students with good entrepreneurial skills, good overall quality so that he can calmly deal with future social challenges, and even through their own businesses to create jobs for students around to ease the pressure of social employment. (2) Independent entrepreneurship can fully mobilize the initiative of college students so as to realize self-worth better. Graduates often start from their own interests, through their own businesses to allow themselves in their favorite areas to fully demonstrate their talent and achieve their desired goals. Solve their own employment problems, but also to better achieve self-worth, and increase personal sense of accomplishment to enhance their social self-confidence. (3) Independent entrepreneurship exercises all aspects of college students' abilities, which can effectively improve their overall quality. The overall quality of college students with the enrollment of colleges and universities is declining. Independently start a business can comprehensively train students ability in all aspects, can effectively improve the overall quality of college students. Students in entrepreneurship activities to expand relationships, increase social experience, develop social skills. Through entrepreneurial practice, college students enhance their psychological endurance, eliminate inner obstacles and make impossible possible through their own efforts. (4) Independent entrepreneurship is conducive to cultivating the innovative spirit of college students. Innovation is the root cause of a country's strength and prosperity. It is the country's most precious spiritual legacy. Entrepreneurship practice is the best and most direct form of social work for college students, can well develop their courage to open up and innovative spirit, so as to train all walks of life have a good overall quality and ability to innovate entrepreneurs

\section{High school students' innovation, entrepreneurial awareness and ability}

Important factors related to learning and work effectiveness is the environment, the environment has a subtle influence. And to provide good environmental support for innovative behavior is to create a good atmosphere of innovation. The sense and inspiration of college students creating their own innovation are more likely to be motivated by a positive and creative environment. This requires: schools should actively cooperate with students to build their own innovation groups, and 
targeted to give guidance and encouragement; students should take the initiative to make good use of the school library, laboratory and other hardware and software aspects Environmental resources. Students should take the initiative to participate in social practice and research, so that the combination of theory and practice. Out of school gate to find problems in social practice, through independent thinking to solve the problem, and timely feedback in practical activities. Learning is a boring and painstaking process of perseverance, requiring students to devote themselves wholeheartedly. All kinds of temptations in social life are ubiquitous. This requires that students have good self-control and self-cultivation. Through exploration and research, they cultivate and discover their true points of interest and translate their interests into persistence and motivation. In addition, students should continually cultivate their own independent thinking and thinking, should be good at using reverse thinking to consider the issue, so that independent thinking has become the driving force for research. Any effective innovation stems from good fundamentals. Laying the foundation for the study of new findings plays a crucial role. Innovation results mostly from the underlying combination of basic thinking under the independent thinking, college students do not have a solid theoretical foundation is difficult to really understand the profound application of technology, it does not mention innovation. Professional courses should pay more attention to the cultivation of practical ability.

Create a high-quality innovative entrepreneurial faculty. First, reduce unnecessary workload of teachers and reduce unnecessary meetings. Teachers should not increase additional tasks for teachers after completing the teaching workload stipulated by the school, and reduce the routine teaching inspection To avoid unnecessary and repetitive work; secondly, to encourage teachers, especially young teachers, to carry out internship in enterprises, regularly participate in training, update their knowledge and expand their horizons. For teacher training, internships to provide funding and time protection, teachers in the process of internships and training in accordance with the normal wage and class work calculations; Third, the establishment of a team of senior experts, with a strong innovation and entrepreneurship guidance full-time teachers. Encourage teachers to participate in entrepreneurial experience and exchange, learn teaching methods and teaching methods about innovation and entrepreneurship education curriculum. Fifth, to deepen the reform of examination methods. Breaking the original assessment model of the terminal assessment, focusing on process assessment, the actual work process based on the tasks, from all levels of assessment, for each process to design a capacity assessment program. Construction of a comprehensive series of activities and professional skills competitions, to achieve the students in school, high school, to do with the test to match the game, to promote the purpose of the game. In this way, comprehensive ability training is also an overall assessment of students' training effect, and finally an all-round, three-dimensional and dynamic evaluation system for innovation and entrepreneurship is finally established.

\section{Conclusion}

Entrepreneurship training is a certain law, its growth is a process. Learning from experience and lessons learned is a natural advantage that college-age entrepreneurs can have over social entrepreneurs. As long as we plan to cultivate students' ability to innovate and start a business, in the future, they will have the opportunity to become a hero and a model for entrepreneurship.

\section{Acknowledgements}

Educational Science in Shaanxi Province "Thirteenth Five-Year Plan" 2017 Project (SGH17H221): Study on Practical Education System of Innovation and Entrepreneurship in Local Colleges and Universities under New Situation

\section{References}

[1] Chen Xiuzhen. Interpretation of the connotation of entrepreneurial ability [J]. Vocational and 
Technical. 2007 (04)

[2] Chen Qinhong. Review of entrepreneurial theory [J]. Mall Modernization. 2006 (21)Journal of Jiangxi Agricultural University (Social Sciences Edition). 2005 (04) [3] Zhang Minglin, Zhang Jinfeng.

[4] Yang Jingwen. Overview of China's entrepreneurship theory and empirical research [J]. Business Research. 2005 (22)

[5] Lin Song, Jiang Yanfu, Zhang Jian. Entrepreneurial Opportunity Identification: Concepts, Processes, Influencing Factors and Analysis Framework [J]. Science of Science and Management in Science and Technology. 2005 (06)

[6] Yang Jun. Study on Entrepreneurial Ability Based on Entrepreneurial Behavior - A Basic Analysis Framework [J] .Journal of Foreign Economics and Management, 2005 (04)

[7] Sun Qiang. Some Thoughts on Cultivation of University Students' Entrepreneurial Ability [J]. Higher Agricultural Education. 2005 (03) 